\title{
Gene polymorphism and some inflammatory biomarkers associated with coronary artery disease in Egyptian Population
}

Faten Zahran ${ }^{* 1}$, Amal F. Gharib ${ }^{2}$ and Asmaa A. Abd-ELslam ${ }^{3}$

${ }^{1,3}$ Department of Chemistry, Faculty of Science, Zagazig University

${ }^{2}$ Department of Biochemistry, Faculty of Medicine, Zagazig University

\section{ART I CLE INFO}

Fibrinogen,

Homocysteine, CRP, Gene

polymorphism, PCR-RFLP
The main objective of our study was to evaluate the correlation between CRP and homocysteine and the susceptibility to coronary artery disease, Our study also aimed to declar the association between fibrinogen gene 455G/A, Methylene tetra hydrofolate reductase (MTHFR) C677T and C-reactive protein (CRP) $+1059 \mathrm{G}>\mathrm{C}$ gene polymorphisms and susceptibility to coronary artery disease in the Egyptian population. Our study involved two groups:50 healthy control (age $38-62$ years, Gp 1), and 50 patients (age 40 - 62, Gp 2) with coronary artery disease. Homocysteine, hs-CRP were detected, fibrinogen 455G/A, MTHFR C677T and CRP+1059G>C polymorphisms were detected based on the Polymerase chain reaction and restriction enzyme fragment length polymorphism (PCR-RFLP) method. Our study showed that homocysteine and C-reactive protein were associated with the incidence of coronary artery disease. Our study also found a significant increase in the fibrinogen $455 \mathrm{G} / \mathrm{A}$ (AA genotype) and the MTHFR C677T gene (TT genotype) in patients compared to the control group. However, there was no significant difference in patients and control group in the $+1059 \mathrm{G}>\mathrm{C}$ polymorphism (CC genotype). We thus concluded that the $455 \mathrm{G} / \mathrm{A}$ and MTHFR C677T polymorphisms were associated with coronary artery disease rather than $+1059 \mathrm{G}>\mathrm{C}$ that seem to be not associated with coronary artery disease.

(C) 2015 Publisher All rights reserved.

\section{INTRODUCTION}

Coronary artery disease (CAD) is the leading cause of death in Western societies. For example, in the United States the total prevalence of CAD is $7.0 \%$ in adults over 20 years of age and it caused about 1 of every 6 deaths in $2007^{[1]}$. It can be viewed to result from a combination of genetic and environmental factors as well as their interactions. Epidemiological studies have identified many traditional risk factors for CAD, including tobacco use, physical inactivity, poor nutrition, obesity, hypertension, high blood cholesterol, and diabetes. In addition to these modifiable risk 
factors, $\mathrm{CAD}$ and its main complication, myocardial infarction (MI), have a strong genetic basis ${ }^{[2]}$.

Biomarkers such as high-sensitivity Creactive protein (hs-CRP), homocysteine and fibrinogen have been emerged for identifying the population with high CAD risk from several cohort studies, independent of the other established risk factors ${ }^{[3,4]}$.

In spite of the clinical impact these emerging biomarkers have, few cohort studies or meta-analyses have validated the effect of biomarkers in the prediction of the CAD risk in Asian population ${ }^{[5]}$.

Circulating plasma fibrinogen levels have been reported to influence both thrombotic mechanisms and the atherosclerotic process $^{[3]}$. The fibrinogen molecule is composed of two identical subunits, and each of these consists of three polypeptide chains: $\mathrm{Aa}, \mathrm{Bb}$ and $\mathrm{c}$. Each chain is coded for by a specific gene situated on chromosome 4 at $4 q 23-32$. It has been demonstrated that the synthesis of the fibrinogen $\mathrm{Bb}$-chain is rate limiting in the synthesis of the mature fibrinogen protein $^{[4]}$. The G-455A polymorphism is located in the promoter region of the fibrinogen $\mathrm{Bb}$ gene. Carriers of the $-455 \mathrm{~A}$ allele at this polymorphic site, about $20 \%$ of the population, have been suggested to have about $7-10 \%$ higher fibrinogen levels than those homozygous for the $-455 \mathrm{G}$ allele ${ }^{[6]}$.

Homocysteine lies at an important metabolic branch point of methionine metabolism, between the re-methylation and trans-sulfuration pathways ${ }^{[7]}$. The gene that encodes methylene tetra hydro folate reductase enzyme (MTHFR), which is involved in the metabolism of homocysteine (Hcy), is of great interest in clinical practice ${ }^{[8]}$. The substitution of cytosine $(\mathrm{C})$ by thymine $(\mathrm{T})$ at nucleotide 677 of the MTHFR gene that converts an alanine to a valine residue was responsible for the thermo-lability of MTHFR ${ }^{[9]}$. Some authors suggested that the homozygosity for the MTHFR C677T polymorphism was associated with an increased risk of coronary heart disease ${ }^{[10]}$.
C-reactive protein (CRP) is the strongest and most significant risk factor of future cardiovascular events among people without overt hyper lipidemia. These last findings support the hypothesis that a low grade subclinical local inflammatory response may be associated with cardiac ischemic events ${ }^{[11]}$. The interplays between genetic and environmental factors are important in the phenotype development of complex trait diseases, such as CAD. Several single nucleotide polymorphisms of the CRP gene have been demonstrated to affect plasma CRP concentration, such as $+1059 \mathrm{G}>\mathrm{C}$ and +1444 $\mathrm{C}>\mathrm{T}$ in exon 2 and intronic $\mathrm{T}>\mathrm{A}$ polymorphisms $^{[12]}$.

The aim of the present study was to investigate the association of plasma homocysteine and hs-CRP with the risk of CAD and fibrinogen 455G/A, MTHFR C677T and $\mathrm{CRP}+1059 \mathrm{G}>\mathrm{C}$ gene polymorphisms with the incidence of CAD.

\section{Subject and Methods}

The study was planned to include 100 subjects; they were classified into the following two groups, 50 each group: Group I (GP1): (control group) included healthy volunteers with ages ranged $(38-62)$ years, Group II (GP2): included patients with ischemic heart disease with age range (40-60) years. All patients and controls had the same life style (non of them was smoker, had excessive alcohol consumption or special dietary habit).

After fourteen hours fasting, $6 \mathrm{ml}$ blood samples were withdrawn by vein puncture from the anti-cupital vein and then the blood samples were aliquoted as follows: $2 \mathrm{ml}$ blood in anticoagulant free tubes for determination of CRP, lipid profile. Blood samples were kept at room temperature for 30 minutes until clot formation, then sera were separated by centrifugation at $3000 \mathrm{rpm}$ aliquoted and kept freeze at $-20^{\circ} \mathrm{C}$ until use. $2 \mathrm{ml}$ blood into disodium ethylene diamine tetra acetic acid (Na2EDTA-2H2O) treated tubes for determination of homocysteine, plasma was separated by centrifugation at $3000 \mathrm{rpm}$, and 
plasma was kept in eppindorf tubes\& stored at $-20^{\circ} \mathrm{C}$ until use. $2 \mathrm{ml}$ blood into an ethylene diamine tetra acetic acid (EDTA) containing tube. A separated aliquot was kept for DNA extraction.

\section{II.1. Biomarkers detection methods:}

lipids were measured by lipoprotein lipase peroxidase according to Fossati method $^{[13]}$, Total cholesterol (TC) by cholesterol oxidase according to Allain $\operatorname{method}^{[14]}$, high density lipoprotein (HDL) by phosphotungstate magnesium chloride methodology according to Lopes-Virella method $^{[15]}$, very low density lipoprotein (VLDL) and low density lipoprotein (LDL) levels were calculated indirectly by means of the Friedwald formula ${ }^{[16]}$ as (VLDL-C $=\mathrm{TG} / 5$ provided $\mathrm{TG}=400 \mathrm{mg} / \mathrm{dL}$ ) and LDL-C $=\mathrm{TC}-$ (HDL-C + VLDL-C). Total plasma homocysteine levels were determined by enzyme linked immunoassay (Cat. No. KA1242Microplate EIA Homocysteine BioRad, USA) based on enzymatic conversion of homocysteine to S-adenosyl homocysteine followed by quantification of S-adenosyl- Lhomocysteine by an enzyme-linked immunoassay according to Frantzen method ${ }^{[17]}$. Serum hs-CRP concentrations were determined using a particle-enhanced immuneturbidimetry assay with a lower detection limit of $0.03 \mathrm{mg} / \mathrm{L}$. hs-CRP was analyzed from frozen, in which CRP has previously been shown to be stable (Cat. No. E29-056 Dade Behring Marburg GMBH, Marburg, Germany) according to Jeppesen $^{[18]}$.

\section{II.2.1. Polymorphism analysis of the fibrinogen 455G/A gene:}

The 455G/A polymorphism of the fibrinogen gene was analyzed by the restriction fragment length polymorphismpolymerase chain reaction (RFLP-PCR) method described by Thomas ${ }^{[19]}$. A DNA fragment of $865 \mathrm{bp}$ was amplified using the forward

primer:

5'- CACTTACTGGGATTTGGATTAC-3' and the reverse primer 5'GGCTGAACCATTTTATCATTTA-3'. The PCR was performed in $50 \mu \mathrm{L}$ reaction mixture using $0.3 \mu \mathrm{g}$ of genomic DNA. Ten microliters of the PCR product was digested with the restriction enzyme HaeIII (New England Bio-Labs, Beverly, MA, USA) and electrophorised on $2 \%$ agarose gels.

\section{II.2.2.Polymorphism analysis of the MTHFR C677T gene:}

The MTHFR C677T polymorphism of the homocysteine gene was analyzed by the restriction fragment length polymorphismpolymerase chain reaction (RFLP-PCR) method described by Frost $^{[9]}$.about 50 to 80 ng DNA samples were amplified in a final volume of $25 \mu \mathrm{L}$ containing $1 \times \mathrm{PCR}$ buffer with $1.5 \mathrm{mmol} / \mathrm{L} \mathrm{MgCl} 2,2$ unit Taq DNA polymerase, $100 \mu \mathrm{mol} / \mathrm{L} \mathrm{dNTP}$, and 0.5 $\mu \mathrm{mol} / \mathrm{L}$ of each primer, Forward: 5'TGAAGGAGAAGGTGTCTGCGGGA-3' and Reverse:5' AGGACGGTGCGGTGAGAGTG3'. The restriction enzyme Hinf I (Promega, UK) was used to distinguish the C677T polymorphism. and the product was electrophorised on $2 \%$ agarose gels.

\section{II.2.3.Polymorphism analysis of the CRP+1059G>C gene:}

The $+1059 \mathrm{G}>\mathrm{C}$ polymorphism of the CRP gene was analyzed by the restriction fragment length polymorphism-polymerase chain reaction (RFLP-PCR) method described by Cao and Hegele ${ }^{[20]}$. about 50 to $80 \mathrm{ng}$ DNA samples were amplified in a final volume of $25 \mu \mathrm{L}$ containing $1 \times \mathrm{PCR}$ buffer with $1.5 \mathrm{mmol} / \mathrm{L} \mathrm{MgCl} 2,2$ unit Taq DNA polymerase, $100 \mu \mathrm{mol} / \mathrm{L} \mathrm{dNTP}$, and 0.5 $\mu \mathrm{mol} / \mathrm{L}$ of each primer, Forward: 5'GATCTGTGTGATCTGAGAAACCTCT-3'

and $\quad$ Reverse:
GAGGTACCAGAGACAGAGACGTG-3'.

The restriction enzyme MaeIII (Promega, UK) was used to distinguish the $+1059 \mathrm{G}>\mathrm{C}$ polymorphism, and the product was electrophorised on $2 \%$ agarose gels.

\section{Statistical analysis:}

Prevalence of alleles and genotype among patients and control subjects were counted and compared with Hardy- Weinberg predictions. Chi-square test $\left(\mathrm{X}^{2}\right.$, Fisher's exact test) was used to test the distribution of the different genotypes in the different groups. For 
correlation studies, Pearson correlation test was used. $\mathrm{P}$ value of $<0.05$ was considered statistically significant. Statistical analysis was performed using SPSS 20 statistical Package. ${ }^{[21]}$

\section{Results}

IV.1.1. Lipid profile indices, Our study showed that the mean values of TC (229.9 \pm 20.1$) \mathrm{mg} / \mathrm{dl}, \operatorname{LDL}(148.1 \pm 17.3) \mathrm{mg} / \mathrm{dl}$ and $\mathrm{TG}(225.8 \pm 57) \mathrm{mg} / \mathrm{dl}$ show significant increase in patients with CAD which amounted to $32.2 \%, 62.2 \%$ and 31.4 compared to control group $(173.9 \pm 13.4) \mathrm{mg} / \mathrm{dl}$, $(91.1 \pm 16.3) \mathrm{mg} / \mathrm{dl}$ and $(171.8 \pm 8.2) \mathrm{mg} / \mathrm{dl}$ while The mean values of HDL showed significant decrease $(36.7 \pm 5.7) \mathrm{mg} / \mathrm{dl}$ in patients which amounted to $2.1 \%$ compared to control group $(48.5 \pm 4.7) \mathrm{mg} / \mathrm{dl}$. As shown in table(1)

IV.1.2. Plasma tHcy, The mean values of tHcy declared significant increase $(19.8 \pm 3.7) \mu \mathrm{mol} / \mathrm{L}$ in patients which amounted to $150.6 \%$ compared to control group (7.9 \pm 1.96$) \mu \mathrm{mol} / \mathrm{L}$. As shown in table(1)

IV.1.3. Serum hs-CRP, The mean values of CRP revealed significant increase $(225.8 \pm 57) \mathrm{ng} / \mathrm{ml}$ in patients which amounted to $174.1 \%$ compared to control group $(171.8 \pm 8.2) \mathrm{ng} / \mathrm{ml}$. As shown in table(1)

\section{IV.2.1.Genotyping of the fibrinogen $455 \mathrm{G} / \mathrm{A}$} gene:

The fragment amplified by PCR contains a constant HaeIII site that acts as an internal control and generates fragments(wild genotype, GG) of 732 and 133 bp. If the polymorphic site is present, HaeIII digestion cleaves the 732 bp fragment to a 382-bp and a 350-bp fragment .,i.e (heterozygote genotype, GA) results in four fragments 133, 732, 382 and $350 \mathrm{bp}$ while the mutant homozygote(AA) results in three fragments 382,350 and $133 \mathrm{bp}$. (Figure 1).

\section{- Frequency of the fibrinogen 455G/A gene:}

Our results showed that the prevalence of the GA genotype was found to be $38 \%$, $40 \%$ in the control and patient group, respectively whereas almost similar mutant homozygous frequencies ( $8 \%$ and $22 \%$ ) were observed in controls and patients, respectively. There was no significant difference regarding the distribution of the GG and GA genotypes in the two studied groups while in the, AA genotype showed a significant difference between the two groups $(\mathrm{P}<0.05)$. A allele frequency was significantly higher in the patient group (42\%) than the control $(27 \%)$ $(\mathrm{p}<0.001$, OR 13.2 (95\% CI, 5.47-31.76) (Table 2).

\section{IV.2.2.Genotyping of the Homocysteine MTHFR C677T gene:}

The fragment amplified by PCR contains a constant Hinf I site that generates The wild genotype (CC) has a single band representing the entire 198-bp fragment, and the heterozygous genotype (CT) results in three fragments of 198, 175 and $23 \mathrm{bp}$ (the third band of 23 base pairs could not be visualized on the agarose gel), while the mutant homozygous for the MTHFR polymorphism results in 2 fragments 175 and $23 \mathrm{bp}$ (Figure 2).

The fragment amplified by PCR contains a constant Maeiii site that generates fragment of The wild type (GG) showing three bands at 310, 233 and 201 base pairs (bps). The heterozygote (GC) showing four bands, at 310, 233, 201 and 434 base pair. The mutant homozygote (CC) showing two bands at 310 and 434 bps (Figure 3).

\section{- Frequency of CRP+1059G>C gene:}

Our results showed that GG genotype occurred most frequently $(88 \%)$ in our population, the $\mathrm{CC}$ genotype was rare $(<1 \%)$ and was considered in conjunction with the heterozygous genotype. The prevalence of the GC genotype was found to be $12 \%, 20 \%$ in the control and patient groups, respectively whereas almost similar wild genotype (GG) frequencies $(88 \%$ and $80 \%)$ were observed in controls and patients, respectively. $\mathrm{C}$ allele showed non significant frequency in the patient group (11\%) compared to the control group $(6 \%),(\mathrm{p}=0.2$, OR $1.6(95 \% \mathrm{CI}, 0.69$ 5.46) (Table 4).

\section{Discussion}

Coronary artery disease (CAD) is the number 1 killer in the world and is felt to be largely preventable. Reduction of known risk factors for CAD such as hypercholesterolemia, 
hypertension, and smoking have been assessed in multiple randomized placebo-controlled clinical trials and is associated with $30 \%$ to $40 \%$ less clinical events such as death and myocardial infarction. Epidemiological and family studies have repeatedly shown that genetic predisposition accounts for $40 \%$ to $60 \%$ of the risk for CAD . Prevention and treatment of CAD to be comprehensive would be expected to also include modification of the effects of these genetic risk factors, analogous to the current treatment of hypercholesterolemia, which is partly genetic and partly environmental. The barrier until 2005 was the lack of technology. The first microarray having 500,000 single-nucleotide polymorphisms (SNPs) as DNA markers became available and within 5 years the results have been nothing short of remarkable. In total, over 1,319 genetic variants have been identified to be associated with increased risk for 160 diseases $^{[22]}$.

Genome-wide association studies for coronary artery disease (CAD) have identified more than 30 variants robustly associated with CAD risk. The majority are not associated with conventional risk factors but highlight novel pathways, including cellular proliferation. Although some risk variants are non synonymous coding variants resulting in an amino acid change in the encoded protein, the majority are in non coding regions of the genome and may encompass multiple signals of variable effect. The use of genetic data for development of new therapies requires the identification of causative genetic variants and elucidation of the molecular mechanisms by which they predispose to $\mathrm{CAD}^{[23]}$. One of the potential candidate gene that account for an inherited predisposition to $\mathrm{CAD}$ is the receptor for advanced glycation end products (gene: AGER and protein: RAGE) which is multilegand receptor, belonging to the immunoglobulin super-family of cell surface molecules. The activation of AGER can evoke A wide range of signaling pathways that tigger inflammation Atherogenesis and vasoconstriction leading to coronary dysfunction, atherosclerosis and thrombosis ${ }^{[24]}$. AGER might be a powerful negative predictor of coronary artery disease $^{[25]}$.

Our results cleared that there was a significant increase in CRP level in patients with CAD than control, this result was in agree with Pankow ${ }^{[26]}$ who believed that the high levels of CRP may be due to that CAD manifestation depends on interactions between environmental and genetic risk factors genetic and environmental factors influence plasma concentration of CRP, the heritability of CRP was 35-40\%.,This fact implies that acquired factors are at least of the same importance as genetic factors in the determination of plasma CRP concentration. Latkovskis ${ }^{[27]}$ and Ferrari $^{[28]}$ show that polymorphisms in the IL1 gene cluster, IL-6, tumor necrosis factor alpha32 and CRP genes were shown to affect the expression of $\mathrm{CRP}^{[29]}$. Also, the $1059 \mathrm{G}$ $>\mathrm{C}$ polymorphism was found to be affecting the stability of CRP mRNA and hence changing the plasma CRP concentration. its impact on plasma CRP concentration may be due to linkage disequilibrium with nearby genetic polymorphisms, especially with those in the promoter region ${ }^{[30]}$. our study was also in line with Frances Wensley and Pei Gao ${ }^{[31]}$ who believed that Blood concentrations of $\mathrm{C}$ reactive protein are strongly and continuously associated with future risk of coronary heart disease, though it is unknown whether this correlation reflects cause and effect and agreed with Pepys and his collegue ${ }^{[32]}$ who clarify that there is interest in the possibility that massively raised concentrations of C-reactive protein at the time of acute ischemic events could contribute to severity and outcome of ischemic lesions.

Our results found that there was a significant increase in homocysteine level in patients with coronary artery disease than controls, our result also in line with Andreassi $^{[33]}$ who believed that the high levels of may be due to that Coronary artery disease (CAD) is the consequence of atherosclerotic plaque disposition on the coronary artery wall and that is due to that an increased homocysteine in the blood is thus related with acute endothelial dysfunction. Brattstrom and Wilcken $^{[34]}$ who highlighted the causal 
relationship between the occurrence of the coronary heart diseases and the high plasma tHcy. It is hypothesized that the high tHcy level induces pro-coagulative effects that result in endothelial damage that could precipitate the rupture of an established atherosclerotic plaque. Tripathi and his collegue $^{[35]}$ found that the average homocysteine level was significantly higher in the patient group than in the control.

Our results also revealed that: First, The mutant fibrinogen 455G/A associated with incidence of cardiovascular disease and this may be due to that the G-455A polymorphism is located in the promoter region of the fibrinogen $\mathrm{Bb}$ gene. Carriers of the $-455 \mathrm{~A}$ allele at this polymorphic site, about $20 \%$ of the population, have been suggested to have about $7-10 \%$ higher fibrinogen levels than those homozygous for the $-455 \mathrm{G}$ allele ${ }^{[4]}$. Considering both the potential effects of the 455A allele on plasma fibrinogen levels and the presumed association between plasma fibrinogen levels and cardiovascular disease, a logical hypothesis would be that the $-455 \mathrm{~A}$ allele in itself is associated with increased risk of cardiovascular disease.

This finding agrees with several other published studies. Van't Hooft ${ }^{[36]}$ reported that the substitution of $\mathrm{G}$ to $\mathrm{A}$ in $-455 \mathrm{~A}$ allele at the G-455A polymorphic site of the fibrinogen $\mathrm{Bb}$-gene increase the rate of the transcription of the fibrinogen Bb-gene. De Maat ${ }^{[37]}$ and his colleges conclude from their data on Dutch male coronary atherosclerotic patients that the AA-455 genotype is related to more severe and rapid progression of coronary atherosclerosis. Green ${ }^{[38]}$ reported an association between G-455A genotype and the progression of coronary artery disease. Chen ${ }^{[39]}$ reported the absence of association between the $b$-chain fibrinogen gene $-148 \mathrm{C} / \mathrm{T}$ polymorphism, while there is susceptibility to the risk of CAD for the G455A polymorphism.

On the contrary, Tybjaerg-Hansen ${ }^{[40]}$ did not find any relationship between this genotype and coronary heart disease in a general Danish population because he emphasize the lack of statistical power to detect genetic risk and point out the need for a larger study that would increase the possibility to detect genotype or allele frequency differences between cases and referents. Leander $^{[41]}$ did not find evidence of an association between the occurrence of the 455A allele and MI in either men or in women Similarly, Kardys ${ }^{[42]}$ showed the specific fibrinogen gene haplotypes were not associated with coronary events.

Second, MTHFR gene polymorphism was associated with the incidence of coronary heart disease in the studied patients and this may be due to the transition of $\mathrm{C}$ by $\mathrm{T}$ in $677 \mathrm{~T}$ allele at the C677T polymorphic site of the MTHFR affect the rate of the homocysteine metabolism causing increase in its level causing hyper homocysteinemia, this result was in agree with Frost ${ }^{[9]}$ who reported that $70 \%$ reduced activity in the TT genotype and $35 \%$ reduced activity in the CT genotype) implies elevated homocysteine levels in these two genotypes. Tripathi ${ }^{[35]}$ found a significantly higher frequency of $\mathrm{T}$ alleles in CAD patients than in controls. OR in this group was 1.75. Other epidemiological studies that estimated the risk of CAD associated with the $\mathrm{T}$ allele showed conflicting results. Notwithstanding, Kerkeni and Alam found this substitution to be a significant risk factor $^{[43,44]}$. On the contrary, on summarizing the results from 8 studies, Kluijtmans ${ }^{[45]}$ encountered no significant difference for the $\mathrm{T}$ allele, although they reported higher frequencies $(31.8 \%$ and $29 \%$ in patient and control group respectively). Mohamed ${ }^{[46]}$ found that there was no significant correlation between high tHcy levels and MTHFR genotypes in patients. This finding is in keeping with a recent report Morelli ${ }^{[47]}$ which found no association between the plasma tHcy and the MTHFR polymorphism most studies did not show an association between the MTHFR polymorphism and subsequent development of cardiovascular diseases. Thogersen $^{[48]}$ evaluated that there was no significant difference between the patients group and the control group regarding the distribution of the TT genotype. 
Third, CRP+1059 G>C gene polymorphism was not associated with the occurrence of coronary heart disease in the studied patients and this due to that CRP 1059 $\mathrm{C}$ allele carrier is associated with lower plasma CRP concentration, while at an older age, the presence of CAD or diabetes is associated with higher plasma CRP concentration. This result was in agree with Dao-Fu Dai ${ }^{[49]}$ who found that CRP gene 1059 $\mathrm{G}>\mathrm{C}$ polymorphism was not associated with $\mathrm{CAD}$, although this polymorphism significantly affected plasma CRP concentration. they also demonstrated that subjects with CAD or MI had significantly higher plasma CRP concentration compared to controls and this finding was in line with Wensley and his colleges ${ }^{[31]}$ whose results indicated that genetically raised concentrations of $\mathrm{C}$ reactive protein were unrelated to conventional risk factors and risk of coronary heart disease. Zee and Ridker ${ }^{[50]}$ reported in prospective studies of Caucasian populations that the CRP gene $1059 \mathrm{G}>\mathrm{C}$ polymorphism, despite affecting plasma CRP concentration, was neither associated with future MI and stroke events, nor with post-angioplasty rest enosis and this results was with those from previous studies that used other methods, such as the null findings of in vivo studies of atherosclerosis that have involved either injection of C-reactive protein in different species or transgenic expression of $\mathrm{C}$ reactive protein in mice and rabbits. ${ }^{[1,52]}$

\section{Conclusion:}

The present study demonstrated that homocystiene, CRP ß-fibrinogen 455G/A and MTHFR C677T gene polymorphisms were associated with the incidence of CAD whereas CRP $1059 \mathrm{G} / \mathrm{C}$ is not associated with CAD in Egyptian population.

\section{Acknowledgement:}

The authors want to thank Dr. Aml Said lecturer of medical biochemistry, faculty of medicine, Zagazig university for her scientific guidance, fruitful discussion and useful continuous assistance during this work and Dr. Amr Abd El-Menam lecturer of cardiology, faculty of medicine, Zagazig university. For his great help and cooperation throughout this work and his scientific support.

REFERENCES[1]Roger VL, Go AS and Lloyd-Jones DM (2011): Heart disease and stroke statisticse2011 update: a report from the American Heart Association. Circulation;123:e18e209.

[2] Marenberg ME, Risch $\mathbf{N}$ and Berkman LF (1994):Genetic susceptibility to death from coronary heart disease in a study of twins. N Engl J Med;330:1041e6

[3] Boekholdt SM, Hack CE, Sandhu MS, Luben R, Bingham SA and Wareham NJ. (2006): C-reactive protein levels and coronary artery disease incidence and mortality in apparently healthy men and women: the EPIC-Norfolk prospective population study 1993-2003. Atherosclerosis; 187: 415-422.

[4] Park CS, Ihm SH, Yoo KD, Kim DB, Lee JM and Kim HY, (2010): Relation between C-reactive protein, homocysteine levels, fibrinogen, and lipoprotein levels and leukocyte and platelet counts, and 10-year risk for cardiovascular disease among healthy adults in the USA. Am J Cardiol; 105: 1284-1288.

[5] Iso H, Cui R, Date C, Kikuchi S and Tamakoshi A. (2009): C-reactive protein levels and risk of mortality from cardiovascular disease in Japanese: the JACC Study. Atherosclerosis; 207: 291297.

[6] Humphries S, Henry J, Montgomery $\mathbf{H}$. (1999): Gene environment interaction in the determination of levels of haemostatic variables involved in thrombosis and fibrinolysis. Blood Coagul Fibrinolysis; 10: S17-S21.

[7] Selhub J. (1999): Homocysteine metabolism. Annu Rev Nutr. 19: 217 - 46.

[8] Andreassi MG, Botto N, Cocci F, Battaglia D, Antonioli E, Masetti S, Manfredi S, Colombo MG, Biagini A and Clerico A. (2003): Methylene tetra hydro folate reductase gene C677T polymorphism, homocysteine, vitamin B12, and DNA damage in coronary artery disease. Hum Genet 112:171-177. 
[9] Frost P, Blom HJ, Milos R, Goyette P, Sheppard CA, Matthews RG, Boers GJ, den Heijer M, Kluijtmans LA and van den Heuvel LP. (1995): A candidate genetic risk factor for vascular disease: a common mutation in methylene tetra hydro folate reductase. Nat Genet.; 10 (1): $111-3$.

[10] Christensen B, Frosst P, Lussier-Cacan S, Selhub J, Goyette P, Rosenblatt DS, Genest J. and Rozen R. (1997): Correlation of a common mutation in the methylene tetra hydro folate reductase gene with plasma homocysteine in patients with premature coronary artery disease. Arterioscler Thromb Vasc Biol.17 (3): 569 $-73$.

[11] Ridker, P.M., Buring, J.E. and Shih, J. (1998): Prospective study of C-reactive protein and the risk of future cardiovascular events among apparently healthy women. Circulation; 98:731-733.

[12] Brull DJ, Serrano N, Zito F, et al, (2003): Human CRP gene polymorphism influences CRP levels: implications for the prediction and pathogenesis of coronary heart disease. Arterioscler Thromb Vasc Biol; 23:2063-9.

[13] Fossati P and Prencipe L (1982): Serum triglyceride determination calorimetrically with an enzyme that provides hydrogen peroxide. Clin Chem 28:2077-2082.

[14] Allain CC, Poon LS, Chan CSG, Richmond W and Fu PC (1974): Enzymatic determination of total serum cholesterol. Clin Chem 20: 470-478.

[15] Lopes-Virella MF, Stone P, Ellis S and Colwell JA (1977): Cholesterol determination in high density lipoprotein separated by three different methods. Clin Chem, 23:882-888.

[16] Friedewald WT, Levy RI and Fredrickson DS. (1972): Estimation of the concentration of low-density lipoprotein cholesterol in plasma, without use of the preparative ultracentrifuge. Clin Chem; 18: 499-502.

[17] Frantzen F, Faaren AL, Alfheim I and Nordhei AK (1998): Enzyme conversion immunoassay for determining total homocysteine in plasma or serum. Clin Chem, 44:311-316.

[18] Jeppesen J, Hansen TW and Olsen MH. (2008): C-reactive protein, insulin resistance and risk of cardiovascular disease: a population-based study. Eur J Cardiovasc Prev Rehabil; 15(5):594-8.

[19] Thomas AE, Green FR, Kelleher CH, et al, (1991): Variation in the promoter region of the beta fibrinogen gene is associated with plasma fibrinogen levels in smokers and non-smokers. Thromb Haemost; 65: 487-90.

[20] Cao H and Hegele RA.(2000): Human C-reactive protein (CRP) 1059G/C polymorphism. J Hum Genet ;45:100-1.

[21] Levesque.(2007): SPSS programming and data management guide for SPSS and user, fourth edition, Chicago;60606:6412.

[22] Robert Roberts, MD, Alexandre F. R. and Stewart (2012): Genes andCoronary Artery Disease . JACC Vol. 60, No. 18

[23]Ruth McPherson (2013): From GenomeWide Association Studies to Functional Genomics: New Insights Into Cardiovascular Disease. Canadian Journal of Cardiology 29. 23-29

[24] Hegab Z, Gibbons S, Neyses $L$ and Mamas MA (2012): Role of advanced glycation endproducts of cardiovascular disease. World J cardiol 4:90-102.

[25] Feng peng, Dan Hu, Nan Jia, Xiaobo Li, Yuqiong Li, Shaoli Chu, Dingliang Zhu, Weifeng Chen, Jinxiu lin, Wenquan liu (2013): Association of four genetic polymorphisms of AGER and its circulating forms with coronary artery disease : a meta analysis. Plosone 8(7):e70834.

[26] Pankow JS, Folsom AR and Cushman M. (2001): Familial and genetic determinants of systemic markers of inflammation: the NHLBI family heart study. Atherosclerosis. 154: 681-9.

[27] Latkovskis G, Licis N and Kalnins U. (2004): C-reactive protein levels and common polymorphisms of the interleukin-1 gene cluster and 
interleukin-6 gene in patients with coronary heart disease. Eur $\mathbf{J}$ Immunogenet; 31:207-13.

[28] Ferrari SL, Ahn-Luong $L$ and Garnero P (2003): Two promoter polymorphisms regulating interleukin-6 gene expression are associated with circulating levels of C-reactive protein and markers of bone resorption in postmenopausal women. $\mathbf{J}$ Clin Endocrinol Metab 88: 255-9.

[29] Suk HJ, Ridker PM and Cook NR. (2005): Relation of polymorphism within the C-reactive protein gene and plasma CRP levels. Atherosclerosis;178:139-45.

[30] Kovacs A, Green F and Hansson LO. (2005): A novel common single nucleotide polymorphism in the promoter region of the $\mathrm{C}$ reactive protein gene associated with the plasma concentration of C-reactive protein. Atherosclerosis. 178:193-8.

[31] Frances Wensley, Pei Gao; Stephen Burgess; Stephen Kaptoge ; Emanuele Di and Angelantonio (2011): Association between $\mathrm{C}$ reactive protein and coronary heart disease: mendelian randomisation analysis based on individual participant data. BMJ. 342:d548

[32] Pepys MB, Hirschfield GM, Tennent GA, Gallimore JR, Kahan MC, Bellotti V(2006): Targeting C-reactive protein for the treatment of cardiovascular disease. Nature. 440:1217-21.

[33]Andreassi MG, Botto N, Cocci F, Battaglia D, Antonioli E, Masetti S, Manfredi S, Colombo MG, Biagini A and Clerico A. (2003): Methylene tetra hydro folate reductase gene C677T polymorphism, homocysteine, vitamin B12, and DNA damage in coronary artery disease. Hum Genet 112:171-177.

[34] Brattstrom L. and Wilcken DE. (2000): Homocysteine and cardiovascular disease: cause or effect? Am J Clin Nutr.72 (2): 315-23.

[35] Tripathi, Satyendra Tewari, Prabhat Kumar Singh and Sarita Agarwal (2010): Association of homocysteine and methylene tetrahydrofolate reductase (MTHFR C677T) gene polymorphism with coronary artery disease (CAD) in the population of North India. Genetics and Molecular Biology, 33, 2, 224-228.

[36] van-t Hooft $F$, von Baar S, Silveira A, Iliadou A, Eriksson P and Hamsten A. (1999): Two common, functional polymorphisms in the promoter region of the beta fibrinogen gene contribute to the regulation of plasma fibrinogen concentration. Arteriosclerosis Thromb Vasc Biol; 19: 3063-70.

[37] De Maat M, Kastelein J, Jukema J, et al, (1998): $-455 \mathrm{G} / \mathrm{A}$ polymorphism of the beta fibrinogen gene is associated with the progression of coronary atherosclerosis in symptomatic men. Proposed role for an acute-phase reaction pattern of fibrinogen. Arteriosclerosis Thromb Vasc Biol; 18: 265-71.

[38] Green FR. (2001): Fibrinogen polymorphisms and atherothrombotic disease. Ann N Y Acad. Sci. 936: 549-59.

[39] Chen XC, Xu MT, Jin LZ, Chen J and Chen WQ. (2008): Association of betafibrinogen gene $-148 \mathrm{C} / \mathrm{T}$ and $-455 \mathrm{G} / \mathrm{A}$ polymorphisms and coronary artery disease in Chinese population: a meta analysis. Sci China C Life Sci. 51: 814820.

[40] Tybjaerg-Hansen A, Agerholm-Larsen B, Humphries S, Abildgaard S, Schnohr P, Nordestgaard B. (1997): A common mutation (G-455A) in the beta fibrinogen promoter is an independentpredictor of plasma fibrinogen, but not of ischemic heart disease. J Clin Invest; 99: 3034-9.

[41] K. Leander, B. Wiman, J. Hallqvist, G. Falk, U. Defaire (2002): The G-455A polymorphism of the fibrinogen $\mathrm{Bb}$-gene relates to plasma fibrinogen in male cases, but does not interact with environmental factors in causing myocardial infarction in either men or women. Journal of Internal Medicine. 252: 332-341.

[42] Kardys I, Uitterlinden AG, Hofman A, Witteman JCM and de Maat MPM. (2007): Fibrinogen gene haplotypes in relation to risk of coronary events and 
coronary and extracoronary atherosclerosis: the Rotterdam Study. Thromb Haemost. 97: 288-295.

[43] Kerkeni M, Addad F, Chauffert M, Myara A, Gerhardt M, Chevenne D, Trivin F, Farhat MB, Miled A and Maaroufi K. (2006): Hyper homocysteinaemia, methylene tetra hydrofolate reductase polymorphism and risk of coronary artery disease. Ann Clin Biochem 43:200-206.

[44] Alam MA, Husain SA, Narang R, Chauhan SS, Kabra $M$ and Vasisht S. (2008): Association of polymorphism in the thermolabile 5, 10-methylene tetra hydro folate reductase gene and hyper homocysteinemia with coronary artery disease.Mol Cell Biochem 310:111-117.

[45] Kluijtmans LA, van den Heuvel LP, Boers GH, Frosst P, Stevens EM, van Oost BA, den Heijer M, Trijbels FJ, Rozen R and Blom HJ. (1996): Molecular genetic analysis in mild hyperhomocysteinemia: a common mutation in the methylenetetrahydrofolate reductase gene is a genetic risk factor for cardiovascular disease. Am J Hum Genet; 58 (1): 35-41

[46] Mohamed El-Sammak, Mona Kandil, Safaa El-Hifni and Randa Hosni, Mahmoud Ragab. (2004): Elevated plasma homocysteine is positively associated with age independent of C677T mutation of the methylene tetra hydrofolate reductase gene in selected Egyptian subjects. Int. J. Med. Sci. 1: 181192.

[47] Morelli VM, Lourenco DM, D'Almeida V, Franco RF, Miranda F, Zago MA, Noguti MA, Cruz $E$ and Kerbauy J. (2002): Hyper homocysteinemia increases the risk of venous thrombosis independent of the C677T mutation of the methylene tetra hydrofolate reductase gene in selected Brazilian patients. Blood Coagul Fibrinolysis. 13 (3): 271-5

[48] Thogersen AM, Nilsson TK, Dahlen G, Jansson JH, Boman K, Huhtasaari F and Hallmans G.(2001): Homozygosity for the C $677 \rightarrow \mathrm{T}$ mutation of 5,10- methylenetetrahydrofolate reductase and total plasma homocyst(e)ine are not associated with greater than normal risk of a first myocardial infarction in northern Sweden. Coron Artery Dis. 12 (2): 85 - 90.

[49] Dao-Fu Dai, Fu-Tien Chiang, JiunnLee Lin, Li-Ying Huang, Chi Ling Chen, Chee-Jen Chang, Ling-Ping Lai, Kwan-Lih Hsu, Chuen Den Tseng, Yung-Zu Tseng and Juey-Jen Hwang. (2007): Human C-reactive Protein (CRP) Gene 1059 G> C Polymorphism is Associated with Plasma CRP Concentration in Patients Receiving Coronary Angiography. J Formos Med Assoc. Vol. 106 ; No 5.

[50] Zee RY and Ridker PM. (2002): Polymorphism in the human C-reactive protein (CRP) gene, plasma concentrations of CRP, and the risk of future arterial thrombosis. Atherosclerosis;162: 217-9.

[51] Kovacs A, Tornvall P, Nilsson R, Tegner J, Hamsten A, Bjorkegren J.(2007):

Human C-reactive protein slows atherosclerosis development in a mouse model with human-like hypercholesterolemia. Proc Natl Acad Sci USA 104:13768-73.

[52] Koike T, Kitajima S, Yu Y, Nishijima K, Zhang J and Ozaki Y(2009):Human C-reactive protein does not promote atherosclerosis in transgenic rabbits. Circulation 2009;120:2088-94. 
Biochemistry Letters

Journal home page:

Table (1): Some demographic data of controls and patients

\begin{tabular}{|c|c|c|c|c|}
\hline \multirow{2}{*}{ Parameters } & \multicolumn{2}{|c|}{ Mean \pm SD } & \multirow{2}{*}{ F-test } & \multirow{2}{*}{$\%$ change } \\
\hline & GP1 $(n=50)$ & GP2 $(n=50)$ & & \\
\hline TC (mg/dl) & $173.9 \pm 13.4$ & $229.9 \pm 20.1^{*}$ & $<0.001$ & 32.2 \\
\hline LDL (mg/dl) & $91.1 \pm 16.3$ & $148.1 \pm 17.3 *$ & $\langle 0.001$ & 62.2 \\
\hline HDL (mg/dl) & $48.5 \pm 4.7$ & $36.7 \pm 5.7 *$ & $<0.001$ & 2.1 \\
\hline TG (mg/dl) & $171.8 \pm 8.2$ & $225.8 \pm 57 *$ & $\overline{<<0.001}$ & 31.4 \\
\hline tHcy $(\mu \mathrm{mol} / \mathrm{L})$ & $7.9 \pm 1.96$ & $19.8 \pm 3.7 *$ & $<0.001$ & 150.6 \\
\hline hi-CRP(ng/ml) & $74.4 \pm 20.1$ & $203.9 \pm 79 *$ & $\overline{<<0.001}$ & 174.1 \\
\hline
\end{tabular}

$(*)$ : Significant difference $(\mathrm{P}<0.05)$

LDL: Low density lipoprotein,

TC: Total cholesterol,

HDL: High density lipoprotein.

This table was calculated using ANOVA test (F-test).

Table (2): The frequency of fibrinogen 455G/A genotyping in studied groups and the results of the Chi square testing comparing each genotype in the two different groups:

\begin{tabular}{|c|c|c|c|c|c|}
\hline Genotyping & $\begin{array}{c}\text { GP1 } \\
n=50, n(\%)\end{array}$ & $\begin{array}{c}\text { GP2 } \\
n=50, n(\%)\end{array}$ & $X^{2}$ & OR $(95 \%$ CI $)$ & $\boldsymbol{P}$ \\
\hline GG & $27(54)$ & $19(38)$ & & & \\
\hline GA & $19(38)$ & $20(40)$ & 1.69 & $1.5(0.63-3.53)$ & 0.19 \\
\hline $\mathbf{A A}$ & $4(8)$ & $11(22)$ & 9.29 & $3.9(1.08-14.14)$ & 0.002 \\
\hline G allele & $73(73)$ & $58(58)$ & & & \\
\hline A allele & $27(27)$ & $42(42)$ & 40.5 & $13.2(5.47-31.76)$ & $<0.001$ \\
\hline
\end{tabular}

***The mean difference is significant at $\mathrm{P}<0.005$

Table (3): The frequency of Homocysteine MTHFR C677T genotyping in the studied groups and the results of the Chi square testing comparing each genotype in the two different groups:

\begin{tabular}{|c|c|c|c|c|c|}
\hline Genotyping & $\begin{array}{c}\text { GP1 } \\
n 50, n(\%)\end{array}$ & $\begin{array}{c}\text { GP2 } \\
n=50, n(\%)\end{array}$ & $X^{2}$ & OR $(95 \%$ CI $)$ & $P$ \\
\hline $\mathrm{CC}$ & $30(60)$ & $21(42)$ & & & \\
\hline $\mathbf{C T}$ & $18(36)$ & $20(40)$ & 2.3 & $1.6(0.68-3.70)$ & 0.13 \\
\hline TT & $2(4)$ & $9(18)$ & 6.42 & $3.9(1.26-32.83)$ & 0.04 \\
\hline C allele & $78(78)$ & $62(62)$ & & & \\
\hline T allele & $22(22)$ & $38(38)$ & 6.09 & $2.17(1.77-4.05)$ & 0.014 \\
\hline
\end{tabular}

*** The mean difference is significant at $\mathrm{P}<0.005$

Table (4): The frequency of each genotype of CRP+1059G $>C$ genotyping in the studied groups and the results of the Chi square testing comparing each genotype in the two different groups 


\begin{tabular}{|c|c|c|c|c|c|}
\hline Genotyping & $\begin{array}{c}\text { GP1 } \\
n=50, n(\%)\end{array}$ & $\begin{array}{c}\text { GP2 } \\
n=50, n(\%)\end{array}$ & $X^{2}$ & OR $(95 \%$ CI $)$ & $\boldsymbol{P}$ \\
\hline GG & $44 \quad(88)$ & $40(80)$ & & & \\
\hline $\mathrm{GC}+\mathbf{C C}$ & $6+0 \quad(12)$ & $9+1 \quad(20)$ & 2.38 & $1.8(0.61-5.50)$ & 0.12 \\
\hline G allele & $94(94)$ & $\begin{array}{lll}89 & (89)\end{array}$ & & & \\
\hline C allele & 6 6 (6) & 11 (11) & 1.6 & $1.9(0.69-5.46)$ & 0.20 \\
\hline
\end{tabular}

$* * *$ The mean difference is significant at $\mathrm{P}<0.005$

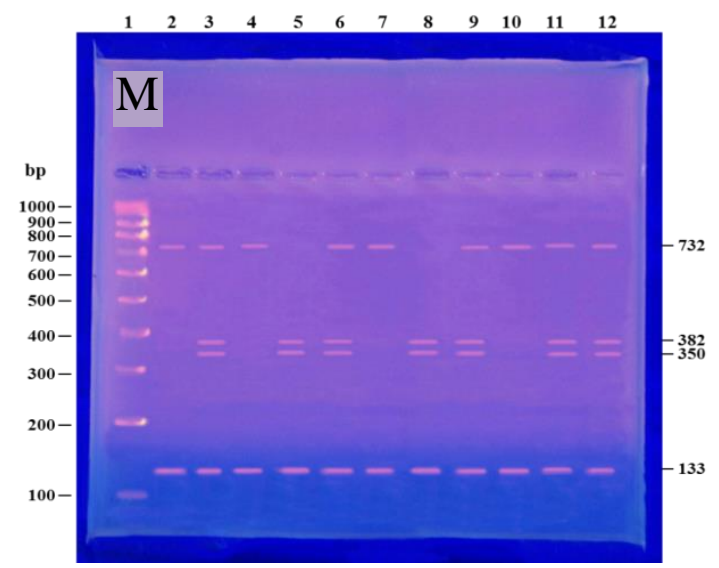

Fig. (1): Fibrinogen 455G/A polymorphism. Lanes 2, 4,7 and 10 show the wild type(GG) genotype, Lanes 3, 6, 9, 11 and 12 show the heterozygote type(GA) genotype, lanes 5 and 8 show the mutant homozygote (AA), M: showing molecular weight Marker.

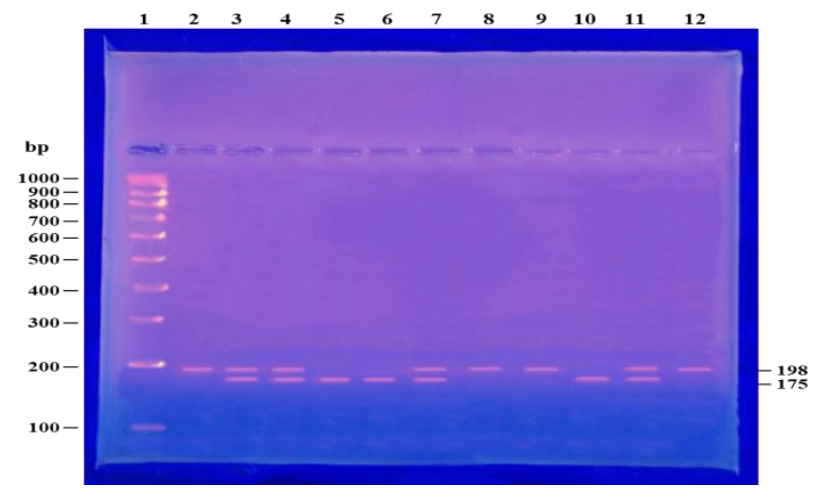

Fig. (2): MTHFR C677T polymorphism, Lanes2, 8, 9and 12 show the wild type(CC) genotype, lanes3, 4, 7and 11 show the heterozygote type(CT) and lanes 5, 6 and 10 show the mutant homozygote (TT), M: showing molecular weight Marker 